\title{
Characterization of Coagulase Negative Staphylococci Isolated From Urine Samples in a Tertiary Care Hospital
}

\author{
T.S. Kumudini ${ }^{1 *}$ and Shivakumar S. Solabannavar ${ }^{2}$ \\ ${ }^{1}$ Department of Microbiology, Vijayanagar Institute of Medical Sciences (VIMS), \\ Bellary-583104, India \\ ${ }^{2}$ Department of Microbiology, S. Nijalingappa Medical College and Hospital, \\ Navanagar, Bagalkot, India \\ *Corresponding author
}

\section{A B S T R A C T}

\section{Keywords}

S. epidermidis,

Linezolid and

Amikacin

Article Info

Accepted:

04 June 2019

Available Online:

10 July 2019
Coagulase negative Staphylococci (CoNS) were generally considered to be contaminants in the past having little clinical significance. Over the past two decades, these organisms have become recognized as important agents of human disease. S. epidermidis is the predominant agent in nosocomial infection, bacteremia, surgical wound and urinary tract infections. Characterization of CoNS isolated from urine samples, their antibiogram and methicillin resistance. The study was conducted from December 2014 to August 2015. We received 518 urine samples, 33 strains of CoNS were isolated. The organisms were identified and speciation was done by standard biochemical reactions. Antibiotic susceptibility testing was done by Kirby-Bauer disk diffusion method and following Clinical laboratory standards institute guidelines (2015). From urine culture, 33/518 (6\%) were obtained as CoNS isolates. From CoNS isolates, majority was in the age group of 014 years $25(76 \%)$. Maximum isolates were from females $20(60 \%)$ than males $13(40 \%)$. The most common species isolated was $S$. epidermidis $18(55 \%)$, followed by $S$. saprophyticus $14(42 \%)$ and S. lugdunensis 1(3\%). Methicillin resistance was found $61 \%$ of strains. Linezolid (100\%), Amikacin (79\%), Doxycycline (76\%), Nitrofurantoin (67\%), Gentamicin $(61 \%)$, Erythromycin and Norfloxacin (each 58\%) and Ciprofloxacin (55\%) were found to be the most effective antibiotics. S. epidermidis was the predominant species isolated and more susceptible antibiotics were Linezolid and Amikacin.

\section{Introduction}

Coagulase negative staphylococci (CoNS) were generally considered to be contaminants in the past having little clinical significance. Over the past two decades, these organisms have become recognized as important agents of human disease. S. epidermidis is the predominant agent in nosocomial infection, bacteremia, surgical wound and urinary tract infections. These mucocutaneous commensals can cause serious invasive infections in NICU patients.1 Clinical studies, have indicated $S$. epidermidis, S. haemolyticus, S. warneri and $S$. hominis as the most prevalent CoNS in hospital infections.2 Methicillin resistance 
among CoNS is particularly important due to cross resistance among betalactam agents and other anti-microbial classes. Susceptibility testing should be done and considered to be a cause of infection due to their resistance to wide spectrum of antimicrobial agents. 3

\section{Objectives}

Characterization of CoNS isolated from urine samples, their antibiogram and methicillin resistance.

\section{Materials and Methods}

This was an observational study and conducted at Department of Microbiology, S Nijalingappa Medical College and Hospital, Bagalkot from December 2014 to August 2015 after obtaining the Institutional Ethical Committee clearance. Clean catch midstream urine was collected in a sterile wide mouth container. 4

The isolates were identified as CoNS by colony morphology, Gram stain, catalase test and coagulase test (slide and tube coagulase). The strains which were slide and tube coagulase negative were selected for further speciation. Speciation was done after reviewing the scheme of Kloos, Schleifer and Koneman et al., 4,5,6 The various biochemical tests used for speciation are as follows: Ornithine decarboxylase test, Phosphatase test, Urease test, Novobiocin susceptibility test, Nitrate reduction test and Carbohydrate fermentation test (Mannose, Mannitol and Xylose).

The antibiotic sensitivity testing was performed on Mueller-Hinton agar by the Kirby-Bauer disc diffusion method, The antibiotics included $\operatorname{Amikacin}(\mathrm{AK})$ ), Amoxicillin-Clavulanate (AMC), Cotrimoxazole (COT), Ciprofloxacin (CIP), Doxycycline (DO), Erythromycin (E),
Gentamicin (GEN), Linezolid (LZ), Norfloxacin (NX), Nitrofurantoin (NIT), Novobiocin (NV) and Cefoxitin7 (CX).

D etection of Methicillin resistance: Cefoxitin $(\mathrm{CX}-30 \mu \mathrm{g})$ was used to identify methicillin resistant coagulase negative Staphylococci (MR-CoNS) 7 and Staphyloccus aureus ATC C 25923 was used as control strain. A $0.5 \mathrm{Mc}$ Farland suspension of the isolate was made and lawn culture done on MHA plate. Plates were incubated at $30^{\circ} \mathrm{C}$ for $18 \mathrm{~h}$ and zone diameters were measured. An inhibition zone of $\geq 22 \mathrm{~mm}$ was considered as susceptible and $\leq 21 \mathrm{~mm}$ resistant for cefoxitin. The results of the test are interpreted as sensitive and resistant as per CLSI Guidelines (2015).7

\section{Results and Discussion}

From urine culture, 33/518 (6\%) were obtained as CoNS isolates. From CoNS isolates, majority was in the age group of 014 years 25(76\%). Maximum isolates were from females $20(60 \%)$ than males $13(40 \%)$. The most common species isolated was $S$. epidermidis 18(55\%), followed by $S$. saprophyticus $14(42 \%)$ and S. lugdunensis 1(3\%). Methicillin resistance was found $61 \%$ of strains. The following antibiotics; Linezolid (100\%), Amikacin (79\%), Doxycycline (76\%), Nitrofurantoin (67\%), Gentamicin $(61 \%)$, Erythromycin and Norfloxacin (each $58 \%$ ) and Ciprofloxacin (55\%) were found to be most effective drugs in our study.

Coagulase Negative Staphylococci form a part of normal flora and CoNS isolated along with another organism, its pathogenic potential may be neglected. Hence it is necessary to speciate CoNS and understand the pathogenic potential of individual CoNS.8 Over the last two decades, especially for the species $S$. epidermidis. S. saprophyticus is an important pathogen in human urinary tract infections, especially in young sexually active females 
and it is resistant to novobiocin. $S$. haemolyticus is another most frequently encountered CoNS species associated with human infections and has been implicated in septicemia, peritonitis, urinary tract, wound, bone and joint infections. 9 S. saprophyticus is a well-documented pathogen causing primary acute urinary tract infections. Uroepithelial tissue, tropism and production of urease contributed to bladder tissue invasion. 4
The CoNS isolates in our study is $6 \%$ and other studies, 32\% Nagasugha et al., ${ }^{9}, 28 \%$ Sardar et al., ${ }^{10}, 20 \%$ according to Golia et al. ${ }^{8}$ and $18 \%$ Jayanthi et al., ${ }^{11}$. In our study, the common species were $S$. epidermidis and $S$. saprophyticus (55\% \& 42\%) respectively. Similarly in other studies by Nagasudha et al., ${ }^{9}\left(59 \%\right.$ \& 22\%), Jayanthi et al., ${ }^{11}$ (56\% \& 7\%), Golia et al., ${ }^{8}$ (46\% \& 28\%) and Sardar et al., ${ }^{10}(43 \%$ \& $16 \%)$ (Table $\left.1-7\right)$.

Table.1 Showing Age wise and Sex wise distribution of CoNS isolates

\begin{tabular}{|l|l|l|l|l|l|l|}
\hline Age groups & Male & Female & Total & \\
\hline In Years & No. & $\%$ & No. & $\%$ & No. & $\%$ \\
\hline $\mathbf{0 - 1 4}$ & 10 & 76 & 15 & 75 & 25 & 76 \\
\hline $\mathbf{1 5 - 4 5}$ & 1 & 8 & 3 & 15 & 4 & 12 \\
\hline $\mathbf{4 6 - 6 0}$ & 1 & 8 & 1 & 5 & 2 & 6 \\
\hline$>\mathbf{6 0}$ & 1 & 8 & 1 & 5 & 2 & 6 \\
\hline Total & $\mathbf{1 3}$ & $\mathbf{1 0 0}$ & $\mathbf{2 0}$ & $\mathbf{1 0 0}$ & $\mathbf{3 3}$ & $\mathbf{1 0 0}$ \\
\hline
\end{tabular}

Table.2 Showing different species of CoNS isolates

\begin{tabular}{|l|l|l|}
\hline Species of CoNS & No. & $\%$ \\
\hline S. epidermidis & 18 & 55 \\
\hline S. saprophyticus & 14 & 42 \\
\hline S. lugdunensis & 1 & 3 \\
\hline Total & $\mathbf{3 3}$ & $\mathbf{1 0 0}$ \\
\hline
\end{tabular}

Table.3 Showing Novobiocin sensitivity

\begin{tabular}{|l|l|l|}
\hline Novobiocin & No. & \% \\
\hline Sensitive & 19 & 58 \\
\hline Resistant & 14 & 42 \\
\hline Total & $\mathbf{3 3}$ & $\mathbf{1 0 0}$ \\
\hline
\end{tabular}

Table.4 Showing Novobiocin sensitivity species wise

\begin{tabular}{|l|l|l|l|l|l|l|}
\hline \multirow{2}{*}{ Species of CoNS } & \multicolumn{2}{l}{ Novobiocin Sensitive } & \multicolumn{2}{l|}{ Novobiocin } & \multicolumn{2}{l|}{ Total } \\
\cline { 2 - 8 } & No. & $\%$ & No. & $\%$ & No. & $\%$ \\
\hline S. epidermidis & 18 & 95 & 0 & 0 & 18 & $\mathbf{5 5}$ \\
\hline S. saprophyticus & 0 & 0 & 14 & 100 & 14 & $\mathbf{4 2}$ \\
\hline S. lugdunensis & 1 & 5 & 0 & 0 & 1 & $\mathbf{3}$ \\
\hline Total & $\mathbf{1 9}$ & $\mathbf{1 0 0}$ & $\mathbf{1 4}$ & $\mathbf{1 0 0}$ & $\mathbf{3 3}$ & $\mathbf{1 0 0}$ \\
\hline
\end{tabular}


Table.5 Showing resistance to Methicillin

\begin{tabular}{|l|l|l|l|l|}
\hline \multirow{2}{*}{$\begin{array}{l}\text { No. of CoNS } \\
\text { isolated }\end{array}$} & \multicolumn{2}{|l|}{ Methicillin Sensitive } & \multicolumn{2}{l|}{ Methicillin Resistant } \\
\cline { 2 - 5 } & No. & $\%$ & No. & $\%$ \\
\hline 33 & 13 & 39 & 20 & 61 \\
\hline
\end{tabular}

Table.6 Showing Methicillin resistance species wise

\begin{tabular}{|c|c|c|c|c|c|c|}
\hline \multirow[t]{2}{*}{$\begin{array}{l}\text { Species of } \\
\text { CoNS }\end{array}$} & \multicolumn{2}{|c|}{ Methicillin Sensitive } & \multicolumn{2}{|c|}{$\begin{array}{l}\text { Methicillin } \\
\text { Resistant }\end{array}$} & \multicolumn{2}{|c|}{ Total } \\
\hline & No. & $\%$ & No. & $\%$ & No. & $\%$ \\
\hline S. epidermidis & 8 & 62 & 10 & 50 & 18 & 55 \\
\hline S. saprophyticus & 4 & 30 & 10 & 50 & 14 & 42 \\
\hline S. lugdunensis & 1 & 8 & 0 & 0 & 1 & 3 \\
\hline Total & 13 & 100 & 20 & 100 & 33 & 100 \\
\hline
\end{tabular}

Table.7 Showing Antibiogram of CoNS

\begin{tabular}{|c|c|c|c|c|}
\hline \multirow[t]{2}{*}{ Antibiotic Discs } & \multicolumn{2}{|c|}{ Sensitive } & \multicolumn{2}{|c|}{ Resistant } \\
\hline & No. & $\%$ & No. & $\%$ \\
\hline Amikacin & 26 & 79 & 7 & 21 \\
\hline $\begin{array}{l}\text { Amoxicillin- } \\
\text { Clavulanate }\end{array}$ & 12 & 36 & 21 & 64 \\
\hline Cotrimoxazole & 12 & 36 & 21 & 64 \\
\hline Ciprofloxacin & 18 & 55 & 15 & 45 \\
\hline Doxycycline & 25 & 76 & 8 & 24 \\
\hline Erythromycin & 19 & 58 & 14 & 42 \\
\hline Gentamicin & 20 & 61 & 13 & 39 \\
\hline Linezolid & 100 & 100 & 0 & $\mathbf{0}$ \\
\hline Norfloxacin & 19 & 58 & 14 & 42 \\
\hline Nitrofurantoin & 22 & 67 & 11 & 33 \\
\hline
\end{tabular}


In our study resistance to methicillin is $61 \%$ and similar to other studies by Aher et al., ${ }^{12}$ $78 \%$, Nagasuda et al., ${ }^{9}-66 \%$, Golia et al., ${ }^{8}$ $66 \%$ and Sardar et al., ${ }^{10}-52 \%$. The following antibiotics Linezolid (100\%), Amikacin (79\%), Doxycycline (76\%), Nitrofurantoin (67\%), Gentamicin (61\%), Erythromycin and Norfloxacin (58\%) and Ciprofloxacin (55\%) were found to be most effective in our study. The antibiogram of our study is similar to other studies by Golia et al., ${ }^{8}$, Nagasudha et al., ${ }^{9}$, Sardar et al., ${ }^{10}$, Jayanthi et al., ${ }^{11}$, Aher et al., ${ }^{12}$ and Kavita et al., ${ }^{13}$.

Methicillin resistant CoNS (MR-CoNS) most notably $S$. epidermidis, $S$. haemolyticus, $S$. hominis are major MR-CoNS and main colonizers of the anterior nares and human skin. Methicillin resistant staphylococcal strains have acquired and integrated into their genome, the staphylococcal cassette chromosome mec (SCCmec), which carries the methicillin resistance (mecA) gene and other antibiotic resistance determinants. 14

S. epidermidis was the predominant species isolated and more susceptible antibiotics were Linezolid and Amikacin. Therefore suggest that CoNS strain should not discard as contaminants and identified up to species level with their antibiogram to decrease morbidity in urinary cases.

\section{References}

1. Almeida RJ, Jorgensen JH. Use of Mueller Hinton agar to determine Novobiocin susceptibility of coagulase negative staphylococci. J Clin Microbiol 1982; 16(6):1155-6.

2. Keim LS, Torres-Filho SR, Vollú Silva P, Teixeira LA. Prevalence, aetiology and antibiotic resistance profiles of coagulase negative staphylococci isolated in a teaching Hospital. Brazilian J Microbiol 2011; 42: 248-55.
3. Woods GL, Hall GS, Rutherford I, Pratt KJ, Knapp CC. Detection of methicillin resistant Staphylococcus epidermidis. J Clin Microbiol 1986; 24(3): 349-52.

4. Washington WC, Allen SD, Janda WM, Koneman EW, Procop GW, Schreckenberger PC. Koneman's Color Atlas and Textbook of Diagnostic Microbiology. $\quad 6^{\text {th }}$ ed. Philadelphia; Lippincott Company JB: 2006.

5. Holt JG, Kreig NR, Sneath PHA, Staley JT, Williams ST. Bergey's Manual of determinative bacteriology. $\quad 9^{\text {th }}$ ed. Baltimore; Lippincott Williams and Wilkins: 1994.

6. Forbes BA, Sahm DF, Weissfeld AS, Bailey and Scott's Diagnostic Microbiology. $13^{\text {th }}$ ed. Missouri: Mosby Elsevier: 2013.

7. CLSI: Performance Standards for antimicrobial susceptibility testing; Twenty- Third Informational Supplement. In CLSI document M100S23 Wayne, PA; Clinical and Laboratory Standards Institute: 2015.

8. Golia S, Telsang DB, Asha S, Kamath B, Tiwari D. Speciation of clinically significant coagulase negative staphylococci and their antibiotic resistant patterns in a tertiary care Hospital. Int J Res Med Sci 2015; 3(5): 1242-46.

9. Nagasudharani J, Vidyarani SU, Suneetha N, Kasturi T, Ramana BV, Kailasanadha Reddy B. Speciation of coagulase negative staphylococci isolated from clinical samples with special reference to their antibiogram. Int J Pharma Res \& Bio Sci 2015; 4(1): 429-38.

10. Sardar SA, Singh M, Basireddy S, Ali $\mathrm{S}$, Kabra V. Coagulase negative staphylococci among clinical isolates in a tertiary care centre. Int J Pharma Bio 
Sci 2015; 6(1): 229-36.

11. Jayanthi RS, Jomy J. Phenotypic characterization of clinically significant coagulase negative staphylococci and their susceptibility pattern in a tertiary care Hospital. Int J Curr Microbiol App Sci 2015; 4(4): 647-52.

12. Aher CS. The isolation pattern, species distribution and antibiotic susceptibility profile of coagulase negative staphylococci: emerging opportunistic pathogens. Int $\mathbf{J}$ of Biomed \& Adv Res 2014; 5(1): 23-5.

13. Kavitha Y, Shaik KM. Speciation and antibiogram of clinically significant coagulase negative staphylococci. Int $\mathbf{J}$ of Health Sci \& Res 2014; 4(12): 15761.

14. Murugesan S, Perumal N, Mahalingam SP, Dilliappan S, Krishnan P. Analysis of antibiotic resistance genes and its associated SCCmec types among nasal carriage of methicillin resistant coagulase negative staphylococci from community settings, Chennai, Southern India. J of Clin Dignostic Res 2015; 9(8): 1-5.

\section{How to cite this article:}

Kumudini, T.S. and Shivakumar S. Solabannavar. 2019. Characterization of Coagulase Negative Staphylococci Isolated From Urine Samples in a Tertiary Care Hospital. Int.J.Curr.Microbiol.App.Sci. 8(07): 74-79. doi: https://doi.org/10.20546/ijcmas.2019.807.010 